
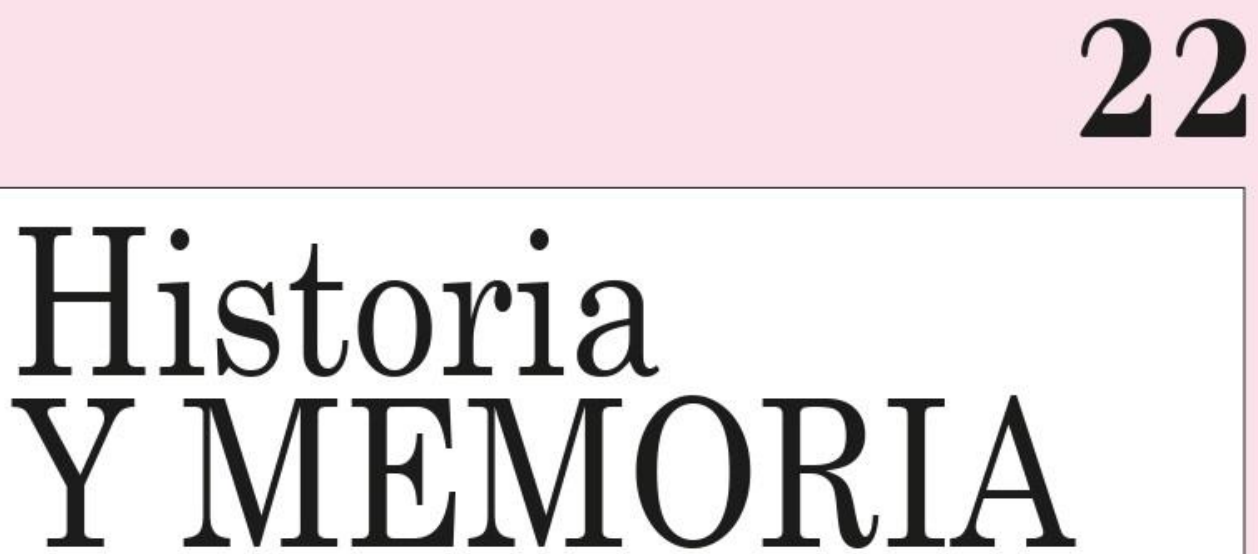

ISSN: 2027-5137

Enero - Junio, Año 2021 - Tunja, Colombia

Asentamiento indígena de Hunza anterior a la conquista. Una mirada desde los imaginarios

https:/doi.org/10.19053/20275137.n22.2021.12097

Jairo Arturo Portilla Tarazona Páginas 399-432

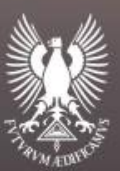




\title{
Asentamiento indígena de Hunza anterior a la conquista. Una mirada desde los imaginarios*
}

\author{
Jairo Arturo Portilla Tarazona ${ }^{1}$ \\ Universidad Pedagógica y Tecnológica de Colombia
}

Recepción: 25/04/2019

Evaluación: 08/07/2019

Aprobación: 03/02/2020

Artículo de Investigación e Innovación

https:/doi.org/10.19053/20275137.n22.2021.12097

\section{Resumen}

El objetivo de esta investigación fue establecer cómo la comunidad indígena de Hunza mantenía en el siglo XVI, a la llegada de los españoles, algunos centros ceremoniales y simbólicos como proceso natural y cultural que hicieron parte de sus imaginarios e identidades colectivas. Al respecto, se abordó el estudio del espacio geográfico del asentamiento de Hunza, de acuerdo con las características físicas del paisaje y su relieve, así mismo, se establecieron relaciones entre el espacio geográfico y los imaginarios construidos por sus habitantes, que son expresión de su cosmogonía.

Palabras clave: Imaginarios, Hunza, espacios físicos, espacios ceremoniales.

\footnotetext{
* El texto se deriva de la investigación titulada: Asentamiento de Hunza anterior a la conquista. Una mirada desde los imaginarios. Asociación Centro de Estudios Regionales (Región).

1 Licenciado en Ciencias Sociales. Estudiante de la maestría en Historia - UPTC. Miembro del grupo de investigación: Asociación Centro de Estudios Regionales (Región). Docente titular del CSV- Tunja y profesor catedrático de Prounal Aracné.凶japata1989@hotmail.com (ㄱ https://orcid.org/0000-0002-1439-2012.
} 


\title{
Hunza indigenous settlement prior to the conquest. An overview from the imaginaries
}

\begin{abstract}
The aim of this investigation was to establish how the Hunza indigenous community maintained their ceremonial and symbolic centres in the 16th century, when the Spanish arrived, as a natural and cultural process that was part of their imaginaries and collective identities. With respect to this, a geographic study of the Hunza settlement was carried out, according to the physical characteristics of the landscape and the terrain, as well as the relationships between the geographical space and the imaginaries created by their inhabitants, which are an expression of their cosmogony.
\end{abstract}

Key words: Imaginaries, Hunza, physical spaces, ceremonial spaces.

\section{Introducción}

Durante la última década han surgido investigaciones ${ }^{2}$ centradas en el estudio de la relación que se establece entre imaginarios sociales y espacio físico, de las comunidades indígenas prehispánicas que ocuparon los territorios actuales de Centroamérica y el Perú. Estas investigaciones se han centrado en el estudio de los imaginarios ${ }^{3}$, que han apreciado en las celebraciones y prácticas-rituales, que se desarrollaban en templos y asentamientos prehispánicos, sobre este particular

\footnotetext{
2 Serge Gruzinski, La colonización de lo imaginario, sociedades indígenas y occidentalización en el México español, siglos XVI-XVIII (México: Fondo de Cultura Económica, 2016). Daniel Hiernaux y Alicia Lindón, «Renovadas intersecciones: La espacialidad y lo imaginario," en Geografía de lo imaginario, dirs. Daniel Hiernaux y Alicia Lindón (Barcelona: Editorial Anthropos, 2012), 9, 28. Paul Claval, «Mitos e Imaginarios en geografía,» en Geografía de lo imaginario, dirs. Daniel Hiernaux y Alicia Lindón (Barcelona: Editorial Anthropos, 2012), 29-48. Martha Ilia Nájera, El sacrificio humano: alimento de los dioses (México: Centros de estudios mayas, UNAM, 1987), 44, 78, 91. Vicent Berdoulay, «El sujeto, el lugar y la mediación del imaginario,» en Geografía de lo imaginario, dirs. Daniel Hiernaux y Alicia Lindón (Barcelona: Editorial Anthropos, 2012), 52.

3 José Cegarra, "Fundamentos teórico epistemológicos de los imaginarios sociales,» Cinta moebio, $\mathrm{n}^{\circ} 43$ (2012): 5.
} 
han resaltado que los indígenas crearon expresiones socioculturales relacionadas con la identidad cultural y social propia de cada comunidad, además de un complejo sistema de relaciones políticas que establecieron en su articulación con otras comunidades indígenas ${ }^{4}$, sobre las cuales se ejercía dominio o subordinación.

En consecuencia, al reflexionar acerca de la importancia de los imaginarios entre las comunidades indígenas surgieron preguntas como: ¿Los imaginarios hicieron parte del sistema de relaciones entre las diferentes comunidades prehispánicas de la región? Y tal vez la pregunta más importante ¿Podría llegar a proponerse una interpretación diferente del asentamiento de Hunza al de centro ceremonial-religioso ${ }^{5}$ De esta manera, se emprendió un estudio minucioso de los imaginarios del asentamiento de Hunza.

Para la realización de esta investigación se analizaron documentos correspondientes a los cronistas Juan de Castellanos, fray Pedro de Aguado, fray Simón Pedro y fray Piedrahita ${ }^{6}$, así como de las actas del Cabildo de Tunja, algunos documentos del AGN, junto con otras fuentes documentales trascritas e investigaciones arqueológicas. Por otro lado, se empleó el sistema de información geográfica, que permitió identificar aspectos fundamentales del paisaje del asentamiento. A nivel metodológico, el artículo utilizó un enfoque etnohistórico utilizando la herramienta "Access» para establecer un

4 Carmen Lucía Díaz, «El cuerpo y el yo: en su origen, lo imaginario,» Colección General Psicoanálisis, no 426 (2014): 38-40.

5 Germán Villate, Tunja Prehispánica. Estudio documental del asentamiento indigena de Tunja (Tunja: Colección: estudios sociales, culturales, de la mujer y de América Latina, 2001), 9-206.

6 La principal dificultad de esta investigación consistió en la carencia de fuentes primarias existentes en archivos históricos que nos permitan comprender los imaginarios particulares de las comunidades indígenas del altiplano Cundiboyacense en Colombia, en este sentido la única forma que existió para acercanos a los imaginarios particulares fue a través de los cronistas religiosos, quienes dedicaron parte de sus obras a describir los mitos y las particularidades de las ceremonias indígenas. 
sistema de comparación entre el estudio geográfico, los reportes arqueológicos y las fuentes documentales. La utilización de estas herramientas facililó la categorización de la información, la interrelación de conceptos, datos y de información sobre el territorio, sobre lo ceremonial y sobre las representaciones; lo que facilitó la comprensión de los imaginarios que construyó la comunidad prehispánica Hunza en el altiplano.

\section{ESPACIO FÍSICO DEL ASENTAMIENTO DE HUNZA ANTES DE LA CONQUISTA DE 1539 (LAS MONTAÑAS Y EL VALLE DEL HUMEDAL)}

Durante el periodo prehispánico las comunidades indígenas se ubicaron en el altiplano Cundiboyacense en las estribaciones de la cordillera Oriental de Colombia, la cual presenta una serie de altiplanos ${ }^{7}$, todos de origen fluviolacustre ${ }^{8}$, donde coincidieron varios cuerpos de agua que conformaron un ecosistema de humedal seco-subhúmedo ${ }^{9}$, representado por afluentes, quebradas, cuerpos de agua y cárcavas ${ }^{10}$. Así mismo, las montañas y cerros fueron elementos físicos esenciales en los asentamientos indígenas del altiplano Cundiboyacense, porque les permitieron a estas comunidades indígenas ubicarse en cercanía a los cuerpos de agua, que se convirtieron en lugares ceremoniales e identitarios para esta comunidad; al respecto, se citan: los

7 Juan Isaza, Los Cerros: Paisaje e identidad cultural Identificación y valoración del patrimonio ambiental y cultural de los cerros orientales en Santa Fe de Bogotá (Bogotá: CIE Centro de Investigaciones Estéticas, Universidad de los Andes, 1999), 18.

8 En relación con ríos y lagos que se forman o recorren dichos valles, siendo parte esencial del paisaje.

9 César Marín y Sandra Parra, Páramos vivos bitácora de flora guía visual de plantas de páramo en Colombia, (Colombia: Instituto de Investigación de Recursos Biológicos Alexander Von Humboldt, 2015), 13.

10 Las cárcavas son surcos producidos por el agua donde el suelo es generalmente arcilloso, tiene como característica la pérdida de capa vegetal que provoca un hundimiento de la tierra entre los surcos debido al constante paso de quebradas o arroyos y por arrastre de sedimentos, formándose en los paisajes con inclinaciones suaves. 
cerros orientales en Bogotá, cerro de Tundama en Duitama ${ }^{11}$ y la montaña o «loma» Cuesta de la Laguna en Tunja.

El paisaje del asentamiento indígena de Hunza estaba conformado por tres montañas ${ }^{12}$, que encerraban el Valle del Humedal conformando así el ecosistema de humedal secosubhúmedo (Ver mapa 1). A continuación, se dará explicación a cada una de las montañas y el valle del paisaje de Hunza, que conformaban el paisaje del asentamiento:

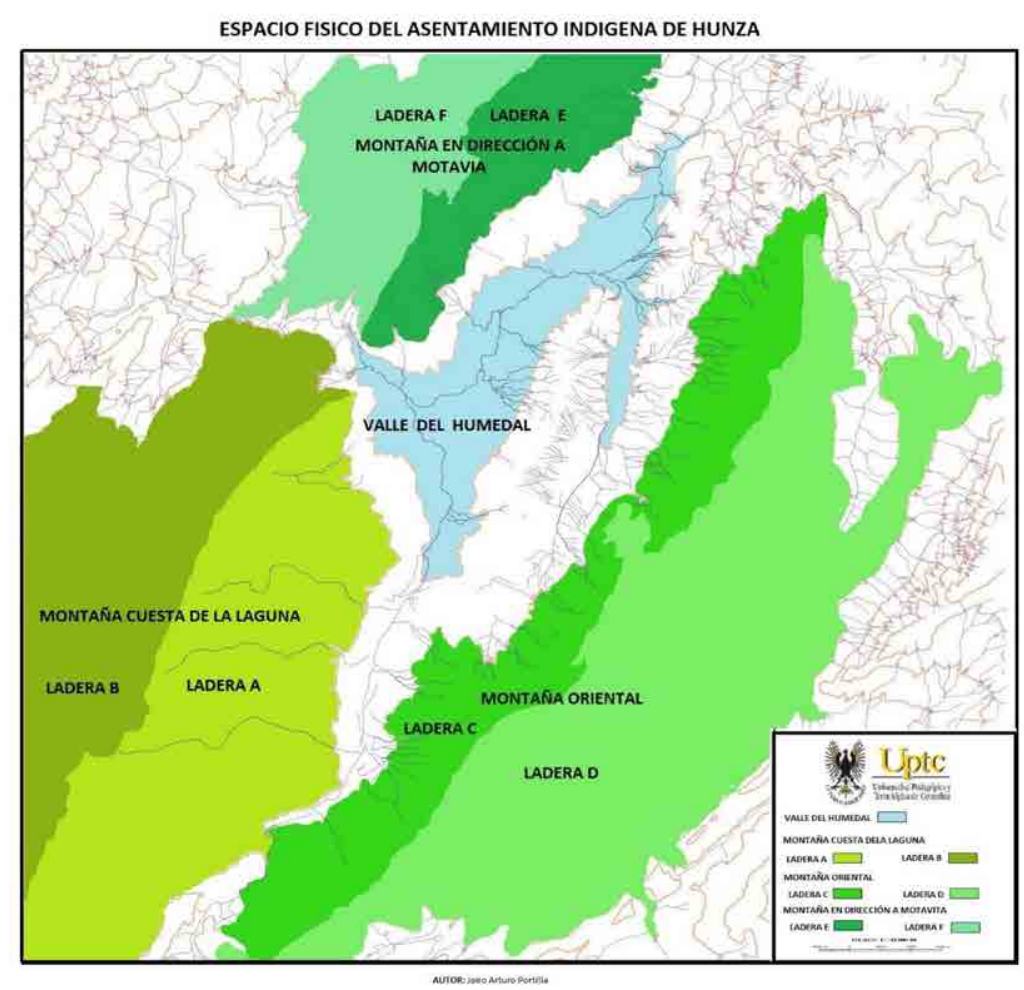

Mapa $1^{13}$ : Espacio físico del asentamiento indígena de Hunza Fuente: mapa elaborado por el autor

11 Isaza, Los Cerros: Paisaje e identidad cultural Identificación, 34-36.

12 Gonzalo Duque, Montañas y teorías orogénicas (Bogotá: Universidad Nacional, 2017), 7.

13 Mapa realizado con el sistema de información geográfica y el software Arcgis 2015, tomando en cuenta las curvas de nivel y la topografía del municipio de Tunja. 
Montaña Cuesta de la Laguna: Esta montaña se encuentra ubicada en la zona occidental del paisaje del asentamiento de Hunza con dos laderas A y B. La zona de ladera A presenta una inclinación suave hasta llegar al Valle del Humedal, mientras que la zona de ladera B presenta menor inclinación siendo esta semiplana, extendiéndose en dirección hacia Cucaita. Esta montaña fue comúnmente referenciada como el «cerro de los ahorcados» descrita así por el cabildo de Tunja:

Señaló por horca de su Majestad para do se cumpla y execute su real justicia tres palos que están puestos en un cerro que está junto a la dicha cibdad (...) En este cabildo proveyeron una estancia y caballería al Regidor Antonio Bermúdez, por el camino de los ahorcados que va hacia Comerriquí (18 de junio y 31 de diciembre de 1539$)^{14}$.

En cuando a las dimensiones físicas, la montaña Cuesta de la Laguna es la que presenta una mayor altura ${ }^{15}$, allí confluían algunas quebradas que descendían por un sistema de cárcavas ${ }^{16}$ que alimentaron el Valle del Humedal. Gracias a esta característica física, a través de la montaña Cuesta de la Laguna fue posible tener una visión completa del paisaje que integró el asentamiento de Hunza (Ver ilustración 1).

Sobre la ladera A de la montaña Cuesta de la Laguna existió un área semiplana ${ }^{17}$, utilizada por los indígenas para edificar varios de los cercados principales del asentamiento, entre los cuales se hallaban el cercado de Quiminza o

14 Acta del Cabildo de Tunja, trascrita por: Enrique Ortega, Libro de Cabildos de la Cibdad de Tunja 1539-1542 (Tunja: Ediciones del Consejo, 1939), 10, 44.

$15 \mathrm{Su}$ punto más alto en los $3.084 \mathrm{msnm}$ y su punto más bajo en los $2.692 \mathrm{msnm}$, alturas con base al sistema de información geográfica de Tunja (TuSIG).

16 Posteriormente, con el reordenamiento del espacio por parte de los españoles, aquellas cárcavas fueron nombrados como los barrancos: la Picota, San Laureano, San Francisco y Santa Lucía que junto con otras estructuras físicas del paisaje servirán como elementos para reorganizar el espacio y los imaginarios de la comunidad indígena de Hunza.

17 Probablemente el área del sector semiplano pudo tener una extensión de 2,314 kilómetros cuadrados con una altura promedio de $2.796 \mathrm{msnm}$; cálculos realizados basándose en las curvas de nivel, tomando el punto de menor altura en sentido oriente al punto de menor altura en sentido nororiente, a través del Sistema de Información Geográfica de Tunja (TuSIG). 
Aquiminzaque, los cercados: Hermano del Zaque, Viejo, Quemuenchatocha, Tunja el Viejo, Boyacá y Auria ${ }^{18}$, así como los respectivos bohíos alrededor de los cercados. En consecuencia, este espacio físico congregó la mayor presencia de los caciques del asentamiento ${ }^{19}$.

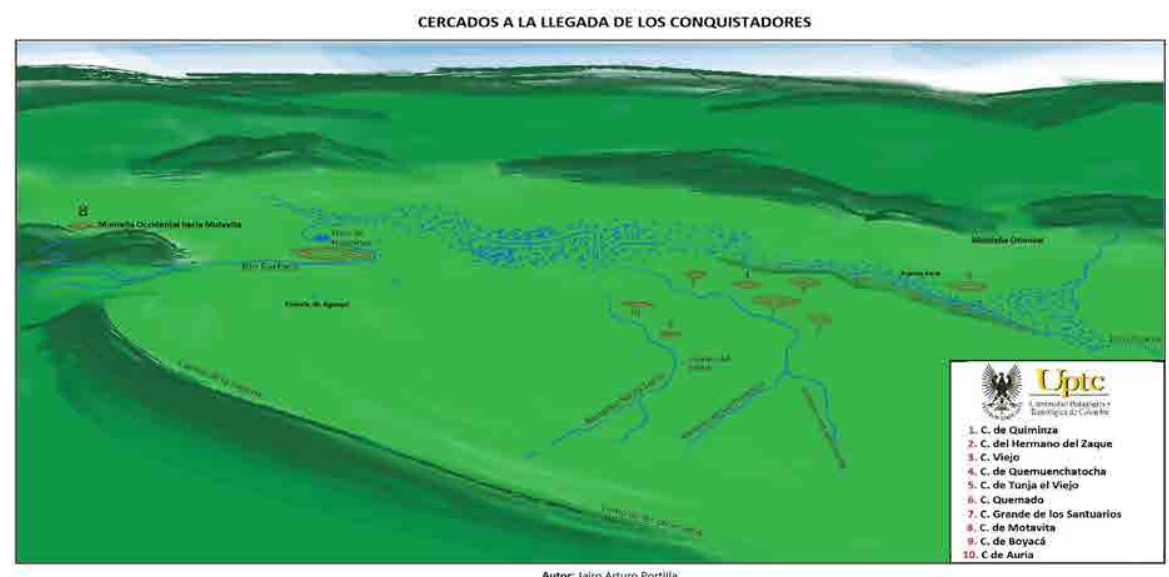

Ilustración $1^{20}$ : Cercado a la llegada de los Conquistadores

Fuente: elaborado por el autor

Montaña oriental: Ubicada por toda la franja oriental del paisaje de Hunza, siendo esta montaña la más extensa del paisaje $^{21}$. Presenta dos laderas C y D; la ladera C con vistas al occidente del paisaje, presenta una inclinación más pronunciada por donde descendían al interior del paisaje varias quebradas que alimentaron el Valle del Humedal; la ladera D mirando en dirección a oriente presenta una inclinación menor, siendo

18 Luis Eduardo Wiesner, Tunja: Ciudad y poder en el siglo XVII (Tunja: Universidad Pedagógica y Tecnológica de Colombia, 2008), 27.

19 Jorge Augusto Gamboa, Los Muiscas en el siglo XVI y XVII: Miradas desde la arqueología, la antropología y la historia (Bogotá: UNIANDES, 2008), 55-74.

20 Representación hecha con base a la proyección satelital con ángulo de 36 grados desde una panorámica actual de la ciudad, los cercados ubicados dentro de la ilustración corresponden a la referencia satelital teniendo en cuenta distancias y áreas aproximadas.

21 La montaña Oriental tiene una altura máxima de $2.840 \mathrm{msnm}$, con una extensión lineal de 12,41 kilómetros, los cálculos fueron basándose en las curvas de nivel. Información suministrada por el Sistema de Información Geográfica de Tunja (TuSIG). 
esta semiplana en dirección a Soracá y Siachoque. Sobre esta montaña se realizaron actividades de intercambio de productos, debido a la proximidad del asentamiento de Hunza a las comunidades indígenas ${ }^{22}$ de Soracá, Oicatá, Siachoque, Chivatá, Viracachá y Toca. Al respecto, el cabildo de Tunja se refirió a aquella área como el cerro de «Trangues» ${ }^{23}$.

[...] le señalaron estancia de la otra parte del arroyo, como van de esta cibdad al pueblo de Ciénega, junto al pueblo de Soracá, que es de Francisco Rodríguez avista del cerro del Trangues, entendiéndose que comienza de una quebrada por donde viene un arroyo de agua [...] la caballería del señor Teniente Hernán Pérez de Quesada, y entra la llanada que está junto al pueblo del Trangues con una fuente [...] (31 de diciembre de 1539$)^{24}$.

La presencia de un mercado «Trangues» o tianguis, podría indicar cómo el asentamiento de Hunza ejerció una gran influencia social y cultural sobre las demás comunidades indígenas; sin embargo, para los españoles los mercados o tianguis fueron escenarios donde se desarrollaron prácticas ceremoniales, relacionadas con la adoración de ciertos ídolos indígenas ${ }^{25}$.

La montaña en dirección a Motavita: Ubicada en la franja occidental en sentido norte contiguo a la montaña Cuesta de la Laguna ${ }^{26}$, presenta dos laderas E y F, La zona E con vistas al occidente del paisaje del valle del humedal, presenta una inclinación muy pronunciada a diferencia de la zona de ladera $\mathrm{F}$, la cual presenta una inclinación semiplana

\footnotetext{
22 Algunas comunidades indígenas que se encontraban periféricas al asentamiento de Hunza, además de las comunidades que a pesar de no ser periféricas fueron señaladas por los españoles como tributarias al cacique del asentamiento.

$23 \mathrm{Al}$ ser una trascripción del acta original, podría haberse cometido una equivocación, puesto que, otros investigadores los referencian como «Tianguis». Páscale Villegas, «Del tianguis prehispánico al tianguis colonial: Lugar de intercambio y predicación (siglo XVI),» Estudios Mesoamericanos, Nueva Época, nº 8 (2010): 98.

24 Acta del Cabildo de Tunja, trascrita por: Ortega, Libro de Cabildos de la Cibdad de Tunja $1539-1542,42$.

25 Villegas, «Del tianguis prehispánico al tianguis colonial,» 94-98.

26 La montaña tiene una extensión de 4 kilómetros 622 metros y una altura máxima de $2.923 \mathrm{msnm}$, los cálculos realizados fueron con base al Sistema de Información Geográfica Tunja (TuSIG).
} 
en dirección hacia Motavita. Entre la montaña Cuesta de la Laguna y la montaña en dirección hacia Motavita existe una depresión, por donde confluye el río Farfacá, el cual atraviesa el Valle de Humedal.

Entre la montaña hacia Motavita y el Valle del Humedal se encontraba el Cercado Grande de los Santuarios, y en la zona alta de la montaña se halló el cercado del cacique de Motavita. Al respecto el Cabildo de Tunja realizó la siguiente mención:

[...] De esta cibdad haya un prado donde se provean los caballos y yeguas que esta [cib]dad hubiere, por tanto, que es bien señalarlo, señalaron por prado a esta dicha [cib]dad dende encima del cercado grande de los santuarios, que está encima del río, a mano izquierda [...] hasta los primeros buhíos que son del cacique Multavita [...] (14 de agosto de $1539)^{27}$.

Probablemente la ubicación intencional del Cercado Grande de los Santuarios, al pie de la montaña en dirección hacia Motavita, estuvo relacionada con su proximidad al río Farfacá $^{28}$, lugares asociados a los mitos originarios de los indígenas de Hunza.

Valle del Humedal: Representaba la zona baja y plana del paisaje ${ }^{29}$ donde confluían los ríos Farfacá y Funzi ${ }^{30}$, además del variado número de quebradas y afluentes que descendían desde las tres montañas del paisaje, así mismo, hacia el interior del valle se hallaba el pozo de Hunzahúa junto con dos nacimientos de agua llamados, en tiempos de la colonia, «fuente Soya» y «fuente Aguayo» ${ }^{31}$. Por otro lado, el Valle del Humedal

27 Acta del Cabildo de Tunja, trascrita por: Ortega, Libro de Cabildos de la Cibdad de Tunja 1539 - 1542, 16

28 Helena Pradilla y German Villate, Pictografías, moyas y rocas del Farfacá (Tunja: Búhos editores Ltda., 2010), 11-148.

29 El Valle del Humedal presenta una altura de $2.682 \mathrm{msnm}$ y una extensión de 13, 91 kilómetros cuadrados basándose en la topografía del sector; así mismo, es probable indicar cómo en los periodos de lluvia la extensión del Valle del Humedal abarcó un espacio más extenso.

30 Actualmente son referenciados como el río la Vega y como el río Jordán.

31 Villate, Tunja Prehispánica. Estudio documental, 121. 
fue el escenario inicial donde se dio origen al imaginario de los indígenas de Hunza. A continuación se dará explicación de la relación que existió entre los escenarios físicos del paisaje y los imaginarios del asentamiento de Hunza.

\section{LAS PRIMERAS PROYECCIONES DEL IMAGINARIO SOBRE EL ESPACIO FÍSICO DE HUNZA}

Los mitos relacionados con el origen del mundo y sus gentes responden a las primeras ocupaciones que hicieron los seres humanos sobre el espacio ${ }^{32}$. Las comunidades prehispánicas, emplearon los mitos para desarrollar prácticas asociadas a sus deidades haciendo de aquellos espacios sagrados lugares de comunicación, festejo y congregación ${ }^{33}$, que hoy son leídos como imaginarios.

Aquellos lugares sagrados correspondían a espacios segmentados $^{34}$, no jerarquizados a diferencia de los representantes de aquellos lugares sagrados, quienes sí adquirían una forma jerárquica (Jeques y caciques ${ }^{35}$ ) para trasmitir las conductas asociadas a sus deidades ${ }^{36}$; que, con el trascurso del tiempo se asentaron como tradiciones e identidades colectivas hasta el punto de volverse parte de la memoria indígena ${ }^{37}$. Los primeros ocupantes del asentamiento de Hunza correspondieron a comunidades indígenas asociadas a la cultura Herrera ${ }^{38}$, quienes habían desarrollado un sistema de agricultura de maíz y tubérculos de altura, así

32 Mircea Eliade (1965) Citada en: Claval, «Mitos e Imaginarios,» 34.

33 Claval, «Mitos e Imaginarios,» 35.

34 Los espacios segmentados residen en un área contigua, la cual puede relacionarse a través de estructuras geomorfológicas como depresiones, vertientes, fallas geológicas, entre otras.

35 En el periodo Colonial, los españoles reconocían a los caciques como los "señores» de las comunidades indígenas, mientras que los jeques como los representantes de la religión de los indígenas.

36 Claval, «Mitos e Imaginarios,» 36-37.

37 Gruzinski, La colonización de lo imaginario, sociedades indígenas, 17.

38 Referenciada así por los primeros hallazgos arqueológicos asociadas a la Laguna de la Herrera en el municipio de Mosquera (Colombia), en Vilma Gómez, Excavación arqueológica de un área residencial en el sitio «El Venado», Valle de Samacá (Bogotá: Universidad de los Andes, 1995), 4. 
como la explotación de salinas y la caza de animales propios del altiplano Cundiboyacense ${ }^{39}$.

En cuanto al espacio geográfico del asentamiento de Hunza, la cultura Herrera se situó entre el 690 a.C al 1.200 d. $\mathrm{C}^{40}$, lo que se ha podido establecer gracias a los hallazgos realizados a complejos cerámicos encontrados en varios emplazamientos, que hoy corresponden al área de estudio del asentamiento de Hunza ${ }^{41}$. En consecuencia, existe la probabilidad de relacionar la cultura Herrera con los mitos originarios y estos asociados al asentamiento de Hunza. De esta manera, dentro del asentamiento de Hunza, sobre el Valle del Humedal, se hallaron representados culturalmente los mitos originarios de Bachué, Bochica, Goranchacha y Hunzahua, que son leídos como imaginarios. A continuación, se dará explicación a cada uno de los mitos y su relación con el espacio.

El mito de Bachué ${ }^{42}$ se situó en el Santuario de Iguaque ${ }^{43}$, sobre este escenario el relato describe cómo una mujer emerge de la laguna con su hijo en brazos, que, al momento de crecer pasa a ser su esposo y con él se da origen a la humanidad, para retornar en su vejez a la laguna. Al respecto, Fray Pedro Simón realizó la siguiente descripción del Mito de Bachué:

llamaban Iguaque, se hace una coronación de empinadas sierras, tierra muy fría y tan cubierta de paramos (...) donde dicen los indios que á poco de como amaneció ó apareció la

39 Hallazgos arqueológicos sugieren que el periodo de la cultura Herrera comprendió entre el I milenio a. C. y el I milenio d. C., en: José Rodríguez, "De la sabana a la selva. Un yacimiento formativo ritual en el entorno de la antigua laguna de la Herrera,» Perspectivas, $\mathrm{n}^{\circ} 19$ (septiembre 2005): 105-106.

40 Neila Castillo, Arqueología de Tunja. Fundación de las investigaciones arqueológicas nacionales (Bogotá: Banco de la República, 1984), 31-45

41 Helena Pradilla y otros, "Arqueología del cercado grande de los santuarios,» Boletín Museo del Oro, $n^{\circ} 32-33$ (1992): 11-206.

42 François Correa, «Sociedad y naturaleza en la mitología muisca,» Tabula Rasa, n 3 (2005): 206, DOI: https://doi.org/10.25058/20112742.235.

43 Actualmente es un parque nacional en Colombia, ubicado a 24 kilómetros de la ciudad de Tunja-Boyacá, creado en 1977, considerado como reservorio de agua, fauna y flora. "Santuario de Flora y Fauna Iguaque,» Parques Nacionales Naturales de Colombia, http//:parquesnacionales.gov.co/portal/region-andina/santuario-de-flora-yfauna-iguaque-2/. 
luz (...) una mujer que llaman Bachué (...) sacó consigo de la mano un niño de entre las mismas aguas (...) hicieron una casa donde vivieron hasta que el muchacho tuvo edad para casarse con ella (...) y los dos muy viejos se volvieron al mismo pueblo (...) convirtiéndose ella y su marido en dos muy grandes culebras, se metieron por las aguas de la laguna, y nunca más parecieron por entonces ${ }^{44}$.

El mito de Bachué se articuló al asentamiento de Hunza a través del valle del humedal por el sistema fluvial del río Farfacá, que desciende desde el santuario de Iguaque hasta el asentamiento de Hunza. Así, el río Farfacá fue la conexión entre dos escenarios físicos segmentados, siendo reconocido como un lugar de identidad cultural para los indígenas de Hunza. Igualmente, es preciso indicar cómo sobre la vertiente del río Farfacá, justo antes de ingresar al Valle del Humedal, existen algunas pinturas de arte rupestre asociadas a la cultura Herrera ${ }^{45}$, por investigadores que en la década de los años 2000 hicieron un trabajo de campo sobre el particular, en cabezado por el extinto profesor Germán Villate ${ }^{46}$.

El mito de Bochica: Tuvo su desarrollo en un amplio territorio del altiplano Cundiboyacense, donde un anciano apareció entre las comunidades indígenas prehispánicas para enseñarles las tradiciones, ceremonias y festejos, así como el oficio de tejer mantas, para finalmente desaparecer al oriente del altiplano Cundiboyacense. Al respecto Fray Pedro Simón realizó la siguiente descripción acerca de Bochica:

Cuentan en cada edad setenta años, un hombre no conocido de nadie, ya mayor y cargado de lanas, el cabello y barba hasta la cintura (...) es aquel Supremo Dios á quien conocían por principio de la luz y de las demás cosas (...) Éste les enseñó hilar algodón y tejer mantas (...) cuando salía de un pueblo les dejaba los telares pintados en alguna piedra lisa y bruñida (...) por si se les olvidaba lo que les enseñaba (...) entró á la Provincia de Tunja y Valle de Sogamoso, á donde se desapareció (...) El Bochica era Dios universal ${ }^{47}$.

44 Fray Pedro Simón, Noticias historiales de las conquistas de Tierra Firme en las Indias Occidentales (Bogotá: Casa editorial de Medrano Rivas, 1891), 281-282.

45 Pradilla y Villate, Pictografías, moyas, 119.

46 Pradilla y Villate, Pictografías, moyas, 24.

47 Simón, Noticias historiales de las conquistas de Tierra Firme, 284, 285, 287. 
Al parecer, para Villate las descripciones de Fray Pedro Simón se relacionaban con las pictografías halladas en las rocas y muros de piedra del río Farfacá; sin embargo, aquellas afirmaciones requerirán su propia investigación en la vinculación entre las pinturas rupestres y los relatos del cronista Fray Pedro Simón.

El mito de Goranchacha: Tuvo lugar inicialmente en el asentamiento indígena de Guachetá ${ }^{48}$, donde Goranchacha fue reconocido como un gran cacique que dominó sobre otras comunidades indígenas, para finalmente establecerse en el asentamiento de Hunza. Al respecto Fray Pedro Simón realizó la siguiente descripción de Goranchacha:

Del pueblo de Guachetá (...) teniendo dos hijas doncellas el Cacique del pueblo (...) á la parte de salir el sol, se recostaban de manera que les pudiese herir con los primeros rayos (...) una fué apareciendo como preñada, que ella decía del sol, y al cabo de nueve meses parió una Guacata, que es en su lengua una piedra de esmeralda grande y rica (...) la trajo algunos días y al final de ellos se halló convertida en criatura (...) á éste llamaron Goranchacha, y lo criaron en la misma casa del Cacique, con título de hijo del sol (...) entrando en Ramiriquí con ella, mató al Cacique, y se hizo obedecer por señor de toda la provincia (...) Vínose luégo á Tunja desde Ramiriquí, donde sentó su casa y Corte ${ }^{49}$.

El mito de Goranchacha se relacionó con el Valle del Humedal, a través de hallazgos arqueológicos ubicados en proximidad del Cercado Grande de los Santuarios, donde se halló una estructura de piedras señaladas por Hernández de Alba como el templo de Goranchacha construido por la cultura Herrera $^{50}$.

El mito de Hunzahua: Tuvo dos acontecimientos que se relacionaron al espacio físico del asentamiento, el primero en cuanto a los sucesos que dieron lugar al origen del pozo

48 Actualmente, es un municipio del departamento de Cundinamarca, ubicado a una distancia de 80 kilómetros de la ciudad de Tunja-Boyacá.

49 Simón, Noticias historiales de las conquistas de Tierra, 230, 321.

50 Hernández de Alba (1937) Citado en: Pradilla y otros, «Arqueología del cercado grande de los santuarios,» 25, 61, 66 . 
de Hunzahua dentro del Valle del Humedal. Al respeto, Fray Simón Pedro realizó la siguiente descripción:

No había más personas que el Cacique de Sogamoso y el de Ramiriquí ó Tunja (...) Estos dos Caciques se dicen que hicieron todas las personas (...) Tunja y Ramiriquí se llamaba Hunzahua (...) Hunza se enamoró de una hermana (...) la madre el mal recado, viéndola que le crecía el vientre y pechos (...) tomó la ana, que es el palo con que se menea la chicha (...) para ampararse del golpe se puso detrás de la gacha donde se hacía (...) descargó sobre ella la ira de a madre, quedando la masa y la chicha derramada y la gacha quebrada (...) se abrió la tierra y recibiendo la chicha, quedó hecho un pozo de ella, aunque convertida en agua ${ }^{51}$.

La cita anterior expone la situación de incesto entre el cacique Hunzahua y su hermana, lo que implicó al segundo acontecimiento dentro del mito la huida de Hunzahua y su hermana del asentamiento. Al respecto, Fray Pedro de Aguado realizó la siguiente descripción:

Subiéndose á la loma que estaba sobre el pueblo (...) echó mil maldiciones á aquel valle, con que quedó estéril (...) determinaron ambos dejar del todo aquella tierra (...) dieron á la señora los dolores de parto, y pariendo un niño (...) lo dejaron convertido en piedra en una cueva (...) llegando por estas tierras de Bogotá (...) por bajo del Salto de Tequendama (...) determinaron convertirse en dos piedras ${ }^{52}$.

Es posible indicar cómo desde el imaginario del mito de Hunzahua los indígenas daban explicación a las características erosionadas del paisaje. Resulta curioso indicar cómo sobre el Valle del Humedal se proyectaron las representaciones de las deidades indígenas del asentamiento, así como la relación cultural que establecieron con el agua convirtiéndose en un elemento de identidad; sin embargo, es interesante proponer la discusión acerca de la existencia de «los dos imaginarios» ${ }^{53}$, es decir, el sincretismo que resultó entre los mitos de los indígenas del altiplano Cundiboyacense y los imaginarios

51 Simón, Noticias historiales de las conquistas de Tierra Firme, 312, 313.

52 Simón, Noticias historiales de las conquistas de Tierra Firme, 314.

53 Dean MacCannell, «Los dos imaginarios,» en Geografía de lo imaginario, dirs.

Daniel Hiernaux y Alicia Lindón (Barcelona: Editorial Anthropos, 2012), 109, 111. 
propios del cronista Fray Pedro Simón, al ser él escritor de los «mitos indígenas» ${ }^{54}$.

\section{ESCENARIOS SIMBÓLICOS Y CEREMONIALES DEL ASENTAMIENTO DE HUNZA}

Es necesario considerar cómo los imaginarios de Hunza no solamente se encontraban relacionados con las formaciones naturales del paisaje, en consecuencia, se llegó a considerar la función social de los cercados y los santuarios dentro del asentamiento, de esta manera, surgióla idea de considerar estas estructuras como los escenarios simbólicos y ceremoniales, que construyeron los indígenas en respuesta colectiva a los imaginarios que asociaban como propios y legítimos ${ }^{55}$. Así los imaginarios fueron un elemento articulador entre las actividades políticas, sociales, culturales y de intercambio de productos que desarrollaban los indígenas. A continuación, se dará explicación:

Los cercados de Hunza: El paisaje de Hunza, estaba compuesto por 10 cercados principales ${ }^{56}$, distribuidos en todo el paisaje físico del asentamiento (Ilustración 1). Asimismo, llegaron a ser escenarios esenciales para las comunidades indígenas, debido al tipo de prácticas que se realizaban dentro de aquellos lugares, puesto que en los cercados confluían varias prácticas que representaban sus imaginarios en torno no solo a sus cosmogonías, sino también en relación con actividades

54 Probablemente los testimonios que registró Fray Pedro Simón en Noticias historiales de la conquista de tierra firme en las Indias Occidentales (1626) fueron realizados con base en las crónicas de Aguado, Castellanos, Medrano y Jiménez de Quesada, lo cual pone en duda la integralidad de los relatos, sin embargo, es importante indicar que durante el siglo XVI existían barreras culturales como el manejo del lenguaje castellano para los indígenas, en este sentido, es mucho más lógico pensar que es durante el siglo XVII los frailes y los cronistas tuvieron mayor acceso a los mitos y leyendas de las comunidades indígenas gracias a los procesos de ladinización. en: Alcaldía Mayor de Bogotá, Cronistas de Indias en la Nueva Granada (1536-1731) (Bogotá: IDARTES, 2013), 58.

55 Investigaciones realizadas por Gruzinski indicaron cómo existió una estrecha relación entre los imaginarios colectivos de las comunidades indígenas de México y su comportamiento cultural al momento de representarlas. Gruzinski, La colonización de lo imaginario, sociedades, 15-41.

56 Villate, Tunja Prehispánica. Estudio documental del asentamiento indígena de Tunja, 111-144. 
cotidianas como las celebraciones, de esta manera, Juan de Castellanos hace referencia:

[...] Más entonces en ellas celebraban las fiestas que tenían de costumbre, con muchos entremeses, juegos, danzas, y rústicas cicutas y zampoñas. E ya cuando llegaban al remate hacían a sus ídolos ofrendas $[\ldots]^{57}$.

La presencia de ídolos dentro de los cercados sugiere que los indígenas de Hunza utilizaban estos espacios para representar sus cosmogonías, es decir los imaginarios relacionados probablemente a Bachué, Bochica y Goranchacha, teniendo en cuenta cómo este último se encontraba en las inmediaciones del Cercado Grande de los Santuarios, que era reconocido como un lugar ceremonial de enterramientos indígenas. Asimismo, el desarrollo de las actividades dentro de los cercados indica cómo los indígenas de Hunza emplearon estos espacios como escenarios de relación social y congregación ceremonial.

En relación con lo anterior, en algunas descripciones, los cronistas mencionaron la presencia de los «gaviales» dentro de los cercados como elementos ceremoniales. Los gaviales fueron postes altos donde al parecer realizaron sacrificios los indígenas, así fue descrito por Restrepo y Juan de Castellanos:

[...] Uno de los sacrificios más comunes y frecuentes era el de la gavia. Dieron este nombre los españoles a unos maderos gruesos, altos y derechos, que veían en muchos partes clavados en las esquinas de los cercados, pintados de colorado y con una garita en la parte alta, que los hacía semejarse a las gavias que se usaban entonces en los mástiles de los navíos. Porque ponían sobre las garitas de aquellos mástiles que ya dijimos algún esclavo vivo y amarrado, tirándole con jáculos agudos, al pie del mástil muchas escudillas que ponían los unos y los otros; y la sangre que el vaso recibían del mísero paciente destilada, los dueños cuyas eran las vasijas ofrecían al torpe santuario con sus ridículas ceremonias $[\ldots]^{58}$.

57 Juan de Castellanos, Elegías de Varones ilustres de Indias (Bogotá: ABC. T. IV, 1955), 194.

58 Castellanos, Elegías de Varones ilustres, ... 194. 
Dichos sacrificios humanos realizados en los gaviales pueden ser definidos como instrumentos cargados de fuerza simbólica ${ }^{59}$, al estar vinculados esencialmente a sus deidades prehispánicas; sin embargo, a pesar de la intensión de los cronistas por señalar los sacrificios de las comunidades indígenas en los cercados, surge la duda acerca de la realización de los sacrificios como una actividad relacionada a las celebraciones indígenas, puesto que en estas descripciones no se establece el número de sacrificios realizados, tampoco en cuáles cercados se hallaban los gaviales, a qué deidades estuvieron relacionadas, ni los meses del año en que se realizaban estas prácticas o si los sacrificios efectivamente fueron vistos por los cronistas, todo lo contrario, las descripciones de los gaviales aparecen de manera incompleta y poco contextualizada.

$\mathrm{Al}$ igual que los sacrificios, dentro de los cercados se realizaron prácticas funerarias y de enterramientos, por ejemplo, en el cercado Grande de los Santuarios se hallaron más de quinientos tumbas indígenas ${ }^{60}$, donde se evidenció una jerarquización en las tumbas y la evolución en las formas de los enterramientos. De esta manera, los enterramientos implicaron la participación colectiva de los indígenas en dichos rituales, la cual incluía la preparación de las tumbas y la elaboración de las herramientas que fueron depositadas ${ }^{61}$, con ello podría señalarse cómo las prácticas funerarias de los indígenas de Hunza obedecieron a una respuesta social común.

En cuanto a la función política, los cercados representaban un sistema jerárquico organizado por un cacique principal, seguido por caciques secundarios que, a su vez podían estar acompañados por sus capitanes, los cuales estaban agrupados en Utas que representaban a los miembros de la comunidad

\footnotetext{
59 Martha Nájera. "El sacrificio humano: alimento de los dioses,» Revista de la Universidad de México: Centros de estudios mayas, $\mathrm{n}^{\circ} 515$ (diciembre de 1993): 24-28. 60 Pradilla y otros, «Arqueología del cercado grande de los santuarios,» 27.

61 Helena y otros, "Arqueología del cercado grande,» 28: «En los enterramientos se encontraban tumbas exteriores, restos de animales y de plantas depositados como ofrendas, pequeños hoyos dejados por postes de posibles barbacoas, tierra compactada con inclusión de materiales orgánicos y restos de combustión. Sobre el piso del Bohío se hallaron hondonadas sobre los cuales se sostenían los muertos, "canales" que unían los diferentes entierros y en el perímetro del bohío, huellas de postes y canales de desagüe».
} 
sujetos por parentesco matrilineal ${ }^{62}$. $\mathrm{Al}$ respeto, los nombres de los caciques asociados al asentamiento de Hunza, antes de la llegada de los españoles en 1539, fueron: Quemuenchatocha o Zaque por los cronistas como el cacique principal, los caciques secundarios Quiminza o Aquiminzaque, Motavita, Boyacá, el hermano del Zaque, Auria y Tunja el Viejo, en cuanto a los capitanes se hallaban Auneme, Nimboche y Siabune. En Hunza existía un cercado abandonado llamado el Cercado Quemado ${ }^{63}$.

Los caciques del asentamiento cumplían varias funciones que fueron canalizadas a través de los cercados, entre aquellas actividades estaba el acopio y redistribución de productos agropecuarios. De esta manera, cuando el cacique realizaba actividades comunitarias o diversas festividades ${ }^{64}$, proporcionaba los alimentos y bebidas que iban a consumirse por la comunidad, así describió Piedrahita las celebraciones dirigidas por los caciques:

[...] Otras de las ceremonias más ostentosas que hacían los mozcas eran las procesiones a que asistían sus Reyes o Caciques, respectivamente en ciertos tiempos del año, especialmente en el de siembras o cosechas, y formábanse estas en ciertas carreras anchas de más por menos media lengua de longitud [...] Dividíanse en cuadricullas y parcialmente con diferentes trajes y disfraces $[\ldots]^{65}$.

Es posible señalar cómo los caciques ejercían funciones ceremoniales, así como la utilización de objetos como trajes y disfraces que representaban aquellos imaginarios. En este sentido, los caciques fueron los representantes de aquellos imaginarios que consideraban las comunidades indígenas como propios, incluso se podría llegar a proponerse cómo el comportamiento de los caciques dentro de los asentamientos estaba condicionado o relacionado al tipo de imaginarios, que estuviesen representados dentro del espacio físico.

62 Gamboa, Los Muiscas en el siglo XVI y XVII, 55-74.

63 Villate, Tunja Prehispánica. Estudio documental del asentamiento, 126-139.

64 Gamboa. Los Muiscas en el siglo XVI y XVII, 83-84.

65 Lucas Fernández de Piedrahita, Historia General de las Conquistas del nuevo

Reyno de Granada (Bogotá: Carvajal, 1986), 79-60. 
En relación con lo anterior, otras investigaciones ${ }^{66}$ realizadas en varios cacicazgos sugirieron cómo el poder de los caciques en las comunidades indígenas estaba condicionado al conocimiento y al desarrollo de prácticas rituales; asimismo indicaron cómo los rituales y las ceremonias que desarrollaron los caciques dentro de sus comunidades les permitía extender su representatividad política, social y política a otras comunidades periféricas del asentamiento ${ }^{67}$. Por ese motivo se llegó a considerar a los imaginarios como elementos fundamentales en la legitimización de los caciques dentro de sus comunidades.

Para finalizar, es necesario mencionar la estructura física de los cercados de Hunza por ser los escenarios simbólicos y ceremoniales del asentamiento. En su estructura externa, los cercados fueron edificaciones de madera, con varios encerramientos antes de llegar a un patio central donde se hallaban varios bohíos (Ilustración 2). Así fueron descritos por el conquistador Gonzalo Jiménez de Quesada:

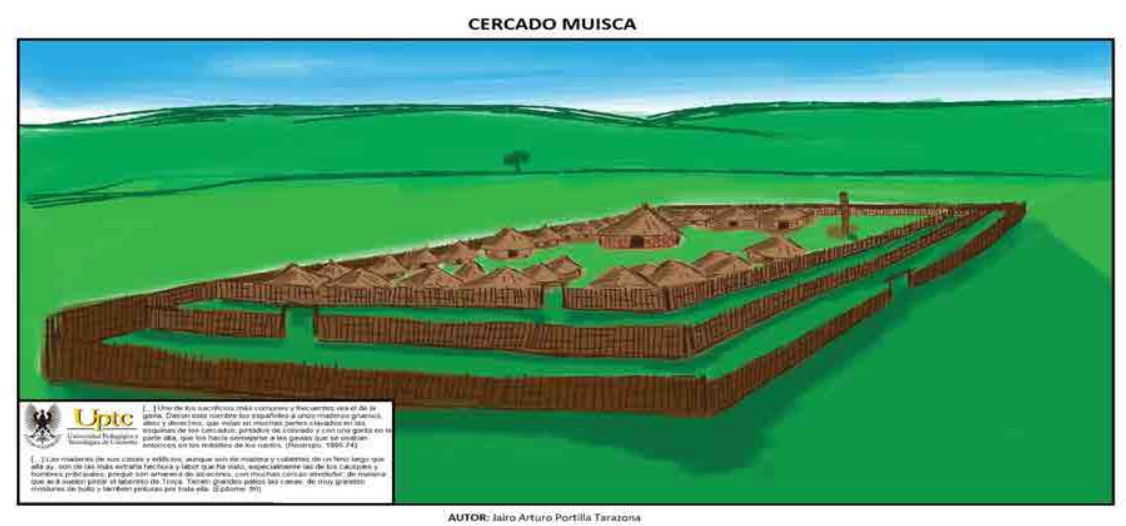

Ilustración $2^{68}$ : Cercado Muisca

Fuente: elaborado por el autor

66 Hope Henderson, «Alimentando la casa, Bailando el asentamiento: Explorando la construcción del Liderazgo político en las sociedades Muiscas,» en Los muiscas en los siglos XVI y XVII: miradas desde la arqueología, la antropología y la historia (Bogotá, D.C.: Universidad de Los Andes, 2008), 48 - 49.

67 Marcela Quiroga Zuluaga, «Las Unidades Sociopolíticas Muiscas en el siglo XVI,» en Los muiscas en los siglos XVI y XVII: miradas desde la arqueología, la antropología y la historia (Bogotá, D.C.: Universidad de Los Andes, 2008), 99.

68 Ilustración con base a las descripciones de la Epítome, Restrepo y Juan de Castellanos. 
[...]Las maderas de sus casas y edificios, aunque son de madera y cubiertas de un feno largo que allá ay, son de las más extraña hechura y labor que ha visto, especialmente las de los caciques y hombres pribcipales, porque son amanera de alcaceres, con muchas cercas alrededor, de manera que acá suelen pintar el laberinto de Troya. Tienen grandes patios las casas, de muy grandes molduras de bulto y también pinturas por toda ella $[\ldots]^{69}$.

Ahora bien, en la estructura interna de los cercados, se hallaban distribuidos bohíos en forma de caracol, con puertas y ventanas que daban al exterior del patio central, así fueron descritos por Piedrahita:

[...] Aunque las labran hoy casi todas cuadradas; cubrianlas de paja porque ignoraban el arte de la teja; las paredes formaban de maderos gruesos, encañados por las partes de fuera y dentro, argamasados con mezcla que hacían de barro y paja. Tenían pequeñas las puertas y las ventanas y dividían el interior de la casa en forma de caracol, en que tenían aposentos y retretes, o dejaban rasas con solo un tabique de carrizo que servía de resguardo para impedir la entrada de los vientos por la puerta y a la vista y registro de los que estaban afuera; y estas puertas labraban de cañas unidas con cordeles de fique, que es a manera de cáñamo, dejándolas a manera de celosía $[\ldots]^{70}$.

La particular estructura externa e interna de los cercados indígenas, podría sugerir una relación con los imaginarios y sus cosmogonías, teniendo en cuenta además el tipo de ceremonias y rituales, que se desarrollaban hacia el interior de los cercados; sin embargo, asegurar aquella interpretación podría requerir de su propia investigación.

Los santuarios fueron otro escenario simbólico y ceremonial de gran importancia dentro del asentamiento de Hunza, reconocido por las comunidades indígenas como el lugar de preparación de los futuros caciques. El propósito de los santuarios consistió en instruir a los individuos que

69 Epítome de la conquista del Nuevo Reino de Granada. Publicado: Colección de documentos inéditos sobre la geografía y la historia de Colombia (Bogotá: Recopilados por Antonio B. Cuervo. Tomo II, 1892), 90.

70 Piedrahita, Historia General de las Conquistas del nuevo Reyno, 72. 
debían ejercer representatividad, en el futuro, dentro de su comunidad, es decir, antes de asumir el papel de cacique en sus comunidades, en aquellos lugares debían aprender a representar los ciclos de la vida y de la muerte, invocar las lluvias, las sequías, sembrar cultivos fértiles y productivos, además de solucionar los problemas de salud y enfermedad. Por consiguiente, los santuarios tuvieron la función de ser el lugar de preparación y adoctrinamiento político y religioso de los jóvenes en la sucesión del poder, además de ser el centro trasmisor de las herencias, de las identidades propias y culturales de la comunidad indígena; es decir de los imaginarios de los asentamientos y sus formas de representarlos, así fue descrito la relación entre los caciques y los santuarios:

[...] Que los caciques de toda esta tierra tienen unas casas que hacen llamar cucas donde meten a sus sobrinos para que allí estén porque han de heredar y que allí ayunan y están uno, dos, y tres años [...] ansy mismo los geques y santeros van de noche a esas casas donde están los sobrinos de los caciques y capitanes que llaman aquellas casas qucas y ally les están predicando $[\ldots]^{71}$.

Por lo tanto, existió una relación política, social, cultural y religiosa entre las actividades que tuvieron lugar dentro de los cercados y el tipo de instrucción que recibieron los caciques de manera previa en los santuarios. Asimismo, los santuarios fueron parte del sistema legítimo y consiente de sucesión matrilineal de los indígenas. Al respecto fray Pedro Simón hizo la siguiente descripción:

[...] También les enseñaba las ceremonias y observaciones de los sacrificios, en que gastaban doce años. Después de los cuales le horadaban las narices y orejas en que les ponían zarcillos y caracuríes de oro e íbanle acompañando muchos indios hasta una quebrada limpia, donde iba con él mismo o con más acompañamiento a la casa del cacique, el cual le daba la vestidura de sacerdocio $[. . .]^{72}$.

71 Pradilla y Villate, Pictografías, moyas y rocas del Farfacá, 122. Infortunamente no hacen referencia si el tipo de cita pertenece a un archivo histórico o los cronistas.

72 Fray Pedro Simón, Noticias historiales de las conquistas de tierra firme en las indias occidentales (Bogotá: Kelly, Edición dirigida por Manuel José Forero. Editores de la revista Bolívar, 1953), 383-384. 
En consecuencia, los santuarios y los cercados funcionaron de manera articulada en la continuidad de los imaginarios, puesto que en aquellos lugares se desarrollaban las actividades simbólicas y ceremoniales como celebraciones, enterramientos, sacrificios, y formas de adoctrinamiento que llegaron a ser representadas por los caciques.

\section{Del modelo celular o modular al esquema en construcción de los imaginarios}

La organización social y política de las comunidades indígenas del altiplano Cundiboyacense en Colombia ha sido abordada en diversos momentos, a mediados de 1950 surgieron esquemas piramidales basados en sistemas feudales o estados confederados para explicar las relaciones de poder entre los indígenas y los caciques ${ }^{73}$, sobre la base de este esquema surgieron otros modelos piramidales, entre los cuales se destacó el modelo de los cacicazgos redistributivos de las comunidades indígenas ${ }^{74}$.

Asimismo, otros investigadores ${ }^{75}$ plantearon modelos no piramidales para dar explicación a elementos culturales y religiosos propios de los indígenas, con base en elementos simbólicos duales ${ }^{76}$, llegando a utilizar incluso elementos de análisis provenientes de otras disciplinas, entre las cuales se utilizó el concepto de territorio tangible e intangible, para dar explicación a las relaciones sociales surgidas entre las comunidades indígenas y el espacio natural que ocuparon ${ }^{77}$.

73 Paradójicamente aún es posible hallar publicaciones recientes con base en el modelo piramidal jerarquizado de hace más de cincuenta años. Miguel Alberto Pérez García, "La organización de los muiscas a la llegada de los españoles,» Revista de Derecho UNED, $\mathrm{n}^{\circ} 20$ (2017): 493, 495-498, DOI: https://doi.org/10.5944/ rduned.20.2017.19489.

74 En investigaciones realizadas por Hermes Tovar y Langebaek se hace referencia a la economía redistributiva de los cacicazgos, modelo adaptado esencialmente con base en los trabajos de John Murra acerca del estado Inca.

75 François Correa Rubio, El sol del poder, simbología y política entre los muiscas del norte de los Andes. (Bogotá: Universidad Nacional de Colombia, 2004), 34, 57, 60, 91. 76 Correa Rubio, El sol del poder, simbología, 36, 43, 186, 335, 364, 376.

77 Patricia Vargas citada en: Carl Henrik Langebaek Rueda, Los muiscas, la historia milenaria de un pueblo Chibcha (Bogotá: Penguin Random House Editorial, S.A.S, 2019), 90 . 
A pesar de la intención de los investigadores por establecer un modelo o esquema que pudiera explicar todos los aspectos relacionados con las comunidades indígenas del altiplano Cundiboyacense, estas presentaban una debilidad tácita, que consistió en no poder establecer un elemento central que permitiera visualizar un todo entretejido y articulado de las comunidades indígenas del altiplano Cundiboyacense en Colombia.

Estudios recientes como el de Jorge Gamboa ${ }^{78}$, se han enfocado en el estudio de los imaginarios, siendo este último el modelo tomdo como referente pare este estudio. Cuando apareció la propuesta de Jorge Gamboa acerca del modelo celular o modular ${ }^{79}$ como esquema de análisis para las comunidades prehispánicas del altiplano Cundiboyacense, se llegó a creer la posibilidad de superar las deficiencias de los modelos anteriores, puesto que a través del modelo celular o modular de Gamboa se reconocían tres elementos esenciales que resultaban estar sujetos y entretejidos entre sí. A continuación, presentaremos los tres elementos principales del modelo celular o modular de Gamboa ${ }^{80}$ : El primero, consistió en el sistema de relaciones sociales y políticas que existió entre las diferentes comunidades indígenas, sin estar necesariamente sujetos por dominación a los asentamientos más grandes y complejos, dado que existían comunidades indígenas que se hallaban subordinados a varios asentamientos mayores. El segundo elemento, reconoció la posibilidad del espacio no dominado, discontinuo y disperso, es decir el control estricto del territorio, puesto que existían comunidades indígenas que se encontraban vinculadas a otros asentamientos, a pesar de existir entre ellas grandes distancias, de esta manera, se reconoció la existencia de comunidades indígenas con autonomía y relativa independencia. El tercer y último elemento, admitía cómo en la estructura interna de las comunidades indígenas se rotaban las funciones políticas, económicas y religiosas. En este sentido el modelo celular o

78 Jorge Augusto Gamboa, El cacicazgo muisca en los años posteriores a la Conquista: del psihipqua al cacique colonial, 1537-1575 (Bogotá: ICANH, 2013), 55.

79 Gamboa. El cacicazgo muisca en los años posteriores a la Conquista, 57-61.

80 Gamboa. El cacicazgo muisca en los años posteriores a la Conquista, 57-59. 
modular de Gamboa permitió visualizar un todo entretejido y articulado de las comunidades indígenas del altiplano Cundiboyacense.

A pesar de los aportes hechos por este modelo celular o modular de Gamboa, aún se conserva el mismo problema de todos los esquemas y modelos anteriores, consistente en la homologación de las estructuras sociales y políticas pertenecientes a otras comunidades prehispánicas del Perú y Centroamérica, para explicar el sistema de relaciones y estructuras de las comunidades indígenas del altiplano Cundiboyacense, debido a que, el modelo celular o modular de Gamboa fue planteado con base en los estudios que realizó James Lockhart ${ }^{81}$ sobre las comunidades nahuas del centro de México. En este sentido, al momento de proponer un esquema en construcción con base en los imaginarios, se debe reconocer el análisis previo que realizó Gamboa con el modelo celular o modular de Lockhart sobre las comunidades indígenas del altiplano Cundiboyacense, puesto que presenta algunas similitudes importantes.

Con respecto al esquema en construcción de los imaginarios resultó necesario plantear tres características principales ${ }^{82}$. La primera característica, consistió en reconocer un proceso previo de ocupación con evidencia arqueológica, donde se pudiera sospechar o comprobar algún tipo de expresión cultural probablemente relacionada a los imaginarios cosmogónicos, asimismo establecer si existía una relación directa entre las estructuras físicas del paisaje como montañas, cerros, ríos, lagunas con aquellos imaginarios ${ }^{83}$, es decir, los imaginarios

81 James Lockhart. Los nahuas después de la conquista: historia social y cultural de los indios de México central, del siglo XVI al XVIII (México: Fondo de cultura económica, 1999), 22-474.

82 Para Mathew Restall la historia de la Conquista ha empleado fundamentalmente fuentes documentales europeas, y ha excluido la comprensión de las fuentes históricas indígenas, a pesar de que la conservación de aquellas fuentes hubiera sido supervisada por los españoles especialmente por clérigos durante el segundo periodo del siglo XVI. Citado en: Diana Magaloni Kerpel, Albores de la Conquista, la historia pintada del Códice Florentino (México: Artes de México, 2016), 13-14.

83 Para Correa «Algunos lugares altos, apartados, lagunas, eran entendidos como portales hacia el más allá; en ellos sé realizada todo tipo de ritualidades y ceremonias, habiéndose figuras antropomorfas y algún tipo de tributo en mantas y 
cosmogónicos de las comunidades indígenas debían habitar y ocupar un espacio físico, dentro o próximo a los asentamientos indígenas.

La segunda, es la fuerza de atracción cultural o social que ejercían aquellos imaginarios sobre otras comunidades indígenas, que permitía establecer una serie de vinculaciones políticas y de intercambios de productos, entre las diferentes comunidades indígenas sin la necesidad de ejercer un dominio, debido a que, los asentamientos que representaban los imaginarios fueron utilizados por las comunidades indígenas como elementos de identidad propia, en consecuencia, se pudieron asociar de manera libre los vínculos naturales que se establecieron al interior de la comunidad, mientras se miraron con detenimiento los impuestos por la fuerza ${ }^{84}$. Asimismo, aquel tipo de vinculaciones políticas podía darse a través de un amplio territorio discontinuo y disperso ${ }^{85}$, entre las diferentes comunidades indígenas.

La tercera y última característica, consistió en el tipo de reconocimiento social y político que obtenían los caciques dentro de sus asentamientos, que fueron identificados a través de los imaginarios. Por ese motivo, los caciques debían adquirir un conocimiento específico sobre las prácticas y lugares ceremoniales, que nos permiten establecer los imaginarios. Estas prácticas las adquirían de manera previa en los santuarios, antes de ser reconocidos legítimamente como caciques dentro de sus asentamientos, asimismo los caciques fueron los responsables de afianzar sus mitos, prácticas ceremoniales y relación con los lugares en sus asentamientos, a través de las prácticas rituales y ceremoniales que dirigían y que son expresión de sus imaginarios, en consecuencia, las funciones religiosas que realizaron los caciques en sus

oro. Simbolizando identidad con su espacio, gentes, manteniendo las relaciones de la comunidad viva con lo dejado por sus antepasados,» en Correa Rubio, El sol del poder, simbología, 86.

84 Durkheim citado en: Francesca Randazzo Eisemann, «Los imaginarios sociales como herramienta,» Revista Imagonautas Vol. 2, n 2 (2012): 80, 87, 90.

85 En este aspecto concordamos con el modelo de celular o modular de Gamboa. 
asentamientos les permitía obtener legitimidad política sobre sus comunidades y sobre otras comunidades indígenas.

De este modo, al aplicar el esquema en construcción con base en los imaginarios para la comunidad indígena de Hunza, se reconocieron estas tres características dentro del asentamiento, es decir, dentro del asentamiento de Hunza se reconoció a través de estudios arqueológicos la ocupación previa de la cultura Herrera ${ }^{86}$, donde aparentemente fueron ellos quienes realizaron las pictografías y moyas del río Farfacá, se asoció a estos la construcción del templo de Goranchacha ${ }^{87}$. Por consiguiente, podría llegar afirmarse que el asentamiento de Hunza fue el centro cultural y social que representó los imaginarios cosmogónicos de Goranchacha, Bachué y Bochica ${ }^{88}$. Es posible asociar el imaginario de Bachué a través de la cuenca del río Farfacá con escenarios físicos relacionados a la geografía del asentamiento.

El asentamiento de Hunza había desarrollado un sistema de vinculaciones políticas y de intercambio de productos con las comunidades indígenas de Sora, Turga, Soracá ${ }^{89}$, Ramiriquí, Guatá, Motavita, Monquirá, Pagasica, Somondoco, Turmequée ${ }^{90}$, Chiquinquirá, Saboyá ${ }^{91}$, Motavita, Boyacá, Duitama, Samacá y Arcabuco, las cuales al parecer se encontraban sujetas al cacique de Hunza. Por otro lado, las distancias que existieron entre estas comunidades indígenas y el asentamiento de Hunza variaban, desde 5 kilómetros lineales hasta los 55 kilómetros lineales, conformando así un territorio discontinuo y disperso; sin embargo, investigaciones previas no han podido demostrar si efectivamente las vinculaciones políticas que existían entre aquellas comunidades y el

86 Gómez, Excavación arqueológica de un área residencial, 4.

87 Hernández de Alba (1937) Citado en: Pradilla y otros, «Arqueología del cercado grande de los santuarios,» 25, 61, 66.

88 Susana Henao, Los hijos del agua (Bogotá: Editorial Planeta, 1995), 19-22, 39, 51, $65,73,85,91,92,140$.

89 Archivo General de la Nación (AGN), Bogotá-Colombia. Encomiendas 11, Tributos, ff8 r. - 303r.

90 Fray Pedro de Aguado. Historia de Santa Marta y el nuevo reino de Granada (Madrid: Establecimiento Tipográfico de Jaime Ratés, Tomo I, 1916), 146.

91 Herrera Ángel, «Milenios de ocupación en Cundinamarca,» 15. 
asentamiento fueron con base en el uso de la fuerza, por ese motivo, se llegó a considerar cómo el asentamiento de Hunza a través de sus imaginarios ejerció una fuerza de atracción social y política sobre aquellas comunidades indígenas que, a su vez se beneficiaban con la realización de intercambios de productos en los mercados indígenas del asentamiento de Hunza $^{92}$.

Por último, la realización de las prácticas y ceremonias que se desarrollaron en Hunza por parte del cacique mayor, indican que la legitimidad política de este dependió enteramente de la fuerza de atracción cultural o social, que ejercieron los imaginarios de Hunza sobre las comunidades indígenas. Asimismo, resulta probable que la presencia de los caciques: Motavita, Boyacá, el hermano del Zaque, Auria, Tunja el Viejo y de los capitanes Auneme, Nimboche y Siabune dentro del asentamiento de Hunza. A pesar de que ellos contaban con sus propios asentamientos en territorios discontinuos y dispersos, sugeriría que estos posiblemente buscaban de alguna manera consolidar su legitimidad política, a través del asentamiento de Hunza y sus imaginarios.

Finalmente, la propuesta del esquema con base en los imaginarios para explicar un todo entretejido y articulado, requerirá de un estudio más amplio, con muchas pruebas arqueológicas e históricas, que permitan desarrollar este esquema a nivel más conceptual y metodológico, que aborde otras reflexiones sobre el particular. Sin desligar la posibilidad de utilizar los imaginarios como elementos centrales, que estructuraban a las comunidades indígenas del altiplano Cundiboyacense de Colombia y por ende del asentamiento de Hunza.

92 Blanca Acuña Rodríguez, «Rutas de circulación e intercambio de sal en la provincia de Tunja, segunda mitad del siglo XVI,» Revista Historia Y MEMORIA, ${ }^{\circ} 16$ (2018): 322, 327, 332, 335, DOI: https://doi.org/10.19053/20275137.n16.2018.7729. Blanca Acuña Rodríguez, Producción y distribución de sal. Pueblo de sal y Chita Ss. XVIXVII (Cali: Universidad del Valle, 2007). 


\section{CONCLUSIÓN}

Los imaginarios son un referente para la comprensión de las estructuras políticas y sociales de las comunidades indígenas del altiplano Cundiboyacense en Colombia, permite el estudio de manera articulada de los elementos físicos del paisaje, las proyecciones físicas sobre el espacio, los escenarios simbólicos y ceremoniales, sin la necesidad de adoptar modelos o esquemas foráneos de otras comunidades prehispánicas. El estudio de los imaginarios abre una ventana de investigación que complemente los anteriores modelos interpretativos acerca de las comunidades prehispánicas del altiplano Cundiboyacense.

Las características propias del paisaje del asentamiento de Hunza y de la región, nutrieron culturalmente de manera paulatina los imaginarios de las comunidades indígenas. Por ese motivo, se pudo establecer cómo los imaginarios originarios prehispánicos residieron de manera abstracta y cultural dentro de los territorios indígenas, y a su vez, se alimentaban de las características propias del paisaje, el que estaba constituido por un paisaje de humedal-seco subhúmedo, rodeado por montañas, cárcavas y afluentes que conformaban no solo el territorio de las comunidades indígenas, sino además el espacio simbólico de sus imaginarios, es decir, el espacio físico de Bachué, Bochica y Goranchacha.

El asentamiento de Hunza fue un escenario donde confluían elementos sociales, culturales, políticos y religiosos con base en los imaginarios que allí se representaron, permitiéndoles así conformar un territorio disperso y discontinuo, sujeto al cacique de Hunza no por medios de dominación, sino por los imaginarios de Hunza sobre las demás comunidades indígenas prehispánicas de la región. Asimismo, podría llegar a proponerse en un futuro próximo como la composición regional del altiplano Cundiboyacense, lo que se estableció con base en los imaginarios que representaban los asentamientos de Bacatá, Hunza y Sogamoso; cada uno de estos asentamientos tienen como característica en común la existencia de imaginarios particulares que fueron reconocidos 
cultural, social y políticamente por otras comunidades indígenas.

En este sentido, podría incluso llegar a afirmarse cómo el papel que llegaron a cumplir los caciques dentro de sus asentamientos estaba relacionado con la capacidad que tuvieron los caciques de reproducir y dominar las prácticas, ceremonias y rituales relacionados a sus imaginarios. Asimismo, es necesario mencionar cómo a través de los imaginarios podría llegar a evaluarse la forma en que se han venido interpretando a los caciques dentro de las comunidades indígenas, puesto que cumplían funciones políticas, religiosas, comerciales, sociales y culturales, llegando a ser probablemente los puentes de comunicación entre los imaginarios ancestrales y los miembros de su comunidad.

Los cercados fueron estructuras a través de las cuales se organizaron las comunidades indígenas en un proceso de complejización. En este aspecto, se puede llegar a indicar como otras comunidades prehispánicas de Centroamérica y el Perú habían realizado dicho proceso de manera previa llegando a identificar templos y edificaciones que les permitían conservar sus identidades culturales. Con lo anterior, se pretende señalar como el asentamiento de Hunza, aunque contaba con sus cercados, aún se hallaba en un proceso de consolidación y complejización cultural.

Finalmente, el estudio de los imaginarios de las comunidades prehispánicas del altiplano Cundiboyacense, también representa una oportunidad para comprender el proceso de la reconfiguración de los imaginarios de las comunidades indígenas durante el siglo XVI, con el arribo de las huestes conquistadoras al Nuevo Mundo, llegando a proponer incluso cómo el éxito de la colonización durante este periodo de tiempo se debió a la reconfiguración de los imaginarios de las comunidades indígenas. 


\section{Referencias}

\section{Fuente primaria}

Archivo General de la Nación(AGN), Bogotá-Colombia. Encomiendas.

Archivo General de la Nación (AGN), Bogotá-Colombia. Caciques e indios (CI).

Acta del Cabildo de Tunja, trascrita por: Ortega, Enrique. Libro De Cabildos De la Cibdad De Tunja 1539-1542. Tunja: Ediciones del Consejo, 1939.

Alcaldía Mayor de Bogotá. Cronistas de Indias en la Nueva Granada (1536-1731). Bogotá: IDARTES, 2013.

Aguado, Fray Pedro de. Historia de Santa Marta y el nuevo reino de Granada. Madrid: Establecimiento Tipográfico de Jaime Ratés, Tomo I, 1916.

Castellanos, Juan de. Elegías de Varones ilustres de Indias. Bogotá: ABC. T. IV, 1955.

Epítome de la conquista del Nuevo Reino de Granada. Colección de documentos inéditos sobre la geografía y la historia de Colombia. Bogotá: Recopilados por Antonio B. Cuervo. Tomo II, 1892.

Piedrahita, Lucas Fernández de. Historia General de las Conquistas del nuevo Reyno de Granada. Bogotá: Carvajal, 1986.

Simón, Fray Pedro. Noticias historiales de las conquistas de Tierra Firme en las Indias Occidentales. Bogotá: Casa editorial de Medrano Rivas, 1891.

. Noticias historiales de las conquistas de tierra firme en las indias occidentales. Bogotá: Kelly, Edición dirigida por Manuel José Forero. Editores de la revista Bolívar, 1953.

\section{Referentes Bibliográficos}

Acuña Rodríguez, Blanca. «Rutas de circulación e intercambio de sal en la provincia de Tunja, segunda mitad del siglo XVI.» 
Historia Y MEMORIA, n 16 (2018): 319-345. DOI: https://doi. org/10.19053/20275137.n16.2018.7729.

Producción y Distribución de sal. Pueblo de la sal Chita S. XVI- XVIII. Cali: Universidad del Valle, 2007.

Berdoulay, Vicent. «El sujeto, el lugar y la mediación del imaginario.» En Geografía de lo imaginario, dirigido por Daniel Hiernaux y Alicia Lindón. Barcelona: Editorial Anthropos, 2012.

Castillo, Neila. Arqueología de Tunja. Fundación de las investigaciones arqueológicas nacionales. Bogotá: Banco de la República, 1984.

Cegarra, José. «Fundamentos teórico epistemológicos de los imaginarios sociales.» Cinta moebio, n 43 (2012): 1-13.

Claval, Paul. "Mitos e Imaginarios en geografía.» En Geografía de lo imaginario, dirigida por Daniel Hiernaux y Alicia Lindón. Barcelona: Editorial Anthropos, 2012.

Correa, François. El sol del poder, simbología y política entre los muiscas del norte de los Andes. Bogotá: Universidad Nacional de Colombia, 2004.

. "Sociedad y naturaleza en la mitología muisca", Tabula Rasa, n 3 (2005): 197-222. DOI: https://doi. org/10.25058/20112742.235.

Díaz, Carmen Lucia. "El cuerpo y el yo: en su origen, lo imaginario.» Colección General Psicoanálisis, nº 426 (2014): 35-52.

Duque, Gonzalo. Montañas y teorías orogénicas. Bogotá: Universidad Nacional, 2017.

Gamboa, Jorge Augusto. Los Muiscas en el siglo XVI y XVII: Miradas desde la arqueología, la antropología y la historia. Bogotá: UNIANDES, 2008.

Gamboa, Jorge Augusto. El cacicazgo muisca en los años posteriores a la Conquista: del psihipqua al cacique colonial, 1537-1575. Bogotá: ICANH, 2013. 
Gómez, Vilma, Excavación arqueológica de un área residencial en el sitio "El Venado", Valle de Samacá. Bogotá: Universidad de los Andes, 1995.

Gruzinski, Serge. La colonización de lo imaginario, sociedades indígenas y occidentalización en el México español, siglos XVIXVIII. México: Fondo de Cultura Económica, 2016.

Henao, Susana. Los hijos del agua. Bogotá: Editorial Planeta, 1995.

Henderson, Hope. «Alimentando la casa, Bailando el asentamiento: Explorando la construcción del Liderazgo político en las sociedades Muiscas.» En Los muiscas en los siglos XVI y XVII: miradas desde la arqueología, la antropología y la historia. Bogotá, D.C.: Universidad de los Andes, 2008.

Herrera Ángel, Martha. "Milenios de ocupación en Cundinamarca.» En Los muiscas en los siglos XVI y XVII: miradas desde la arqueología, la antropología y la historia, coordinado por Jorge Gamboa. Bogotá: Universidad de los Andes, Facultad de Ciencias Sociales, Departamento de Historia, Departamento de Filosofía, CESO, Ediciones Uniandes, 2008.

Hiernaux, Daniel, y Alicia Lindón. «Renovadas intersecciones: La espacialidad y lo imaginario.» En Geografía de lo imaginario, dirigido por Daniel Hiernaux y Alicia Lindón. Barcelona: Editorial Anthropos, 2012.

Magaloni Kerpel, Diana. Albores de la Conquista, la historia pintada del Códice Florentino. México: Artes de México, 2016.

Nájera, Martha. «El sacrificio humano: alimento de los dioses.» Revista de la Universidad de México: Centros de estudios mayas. $\mathrm{n}^{\circ} 515$ (diciembre de 1993): 23-38.

El sacrificio humano: alimento de los dioses (México: Centros de estudios mayas, UNAM, 1987), 44, 78, 91

Isaza, Juan. Los Cerros: Paisaje e identidad cultural Identificación y valoración del patrimonio ambiental y cultural de los cerros orientales en Santa Fe de Bogotá. Bogotá: CIE Centro de Investigaciones Estéticas, Universidad de los Andes, 1999. 
Langebaek, Carl Henrik. Los muiscas, la historia milenaria de un pueblo Chibcha. Bogotá: Penguin Random House Editorial, S.A.S, 2019.

Lockhart, James. Los nahuas después de la conquista: historia social y cultural de los indios de México central, del siglo XVI al XVIII. México: Fondo de Cultura Económica, 1999.

Maccannell, Dean. "Los dos imaginarios.» En Geografía de lo imaginario, dirigido por Daniel Hiernaux y Alicia lindón. Barcelona: Editorial Anthropos, 2012.

Marín, César, y Sandra Parra. Páramos vivos bitácora de flora guía visual de plantas de páramo en Colombia. Colombia: Instituto de Investigación de Recursos Biológicos Alexander Von Humboldt, 2015.

Pérez García, Miguel Alberto. «La organización de los muiscas a la llegada de los españoles.» Revista de Derecho UNED, $\mathrm{n}^{\mathrm{o}} 20$ (2017): 479-498. DOI: https://doi.org/10.5944/ rduned.20.2017.19489.

Pradilla, Helena, y otros. "Arqueología del cercado grande de los santuarios.» Boletín Museo del Oro, n 32-33 (1992): 11-206.

Pradilla, Helena, y Germán Villate. Pictografías, moyas y rocas del Farfacá. Tunja: Búhos editores Ltda, 2010.

Quiroga Zuluaga, Marcela. «Las Unidades Sociopolíticas Muiscas en el siglo XVI.» En Los muiscas en los siglos XVI y XVII: miradas desde la arqueología, la antropología y la historia. Bogotá, D.C.: Universidad de Los Andes, 2008.

Randazzo Eisemann, Francesca. «Los imaginarios sociales como herramienta.» Revista Imagonautas Vol. 2, nº 2 (2012): 77-96.

Rodríguez, José. «De la sabana a la selva. Un yacimiento formativo ritual en el entorno de la antigua laguna de la Herrera.» Perspectivas, $\mathrm{n}^{\circ} 19$ (septiembre 2005): 102-131.

Villate, Germán. Tunja Prehispánica. Estudio documental del asentamiento indígena de Tunja. Tunja: Colección: estudios sociales, culturales, de la mujer y de América Latina, 2001. 
Villegas, Páscale, «Del tianguis prehispánico al tianguis colonial: Lugar de intercambio y predicación (siglo XVI).» Estudios Mesoamericanos, Nueva Época, nº 8 (2010): 93-101.

Wiesner, Luis Eduardo. Tunja: Ciudad y poder en el siglo XVII. Tunja: Universidad Pedagógica y Tecnológica de Colombia, 2008.

\section{Sitio Web}

Parques Nacionales Naturales de Colombia. «Santuario de Flora y Fauna Iguaque.» http://parquesnacionales.gov.co/portal/ region-andina/santuario-de-flora-y-fauna-iguaque- $2 /$.

\section{Citar este Texto}

Portilla, Jairo Arturo. "Asentamiento indígena de Hunza anterior a la conquista. Una mirada desde los imaginarios.» Historia Y MEMORIA, n 22 (2021): 399-432. DOI: https:/doi. org/10.19053/20275137.n22.2021.12097. 